\title{
Impact of Red Cell and Platelet Distribution Width in Patients of Medical Intensive Care Unit
}

\author{
Ayush Dubey ${ }^{1}$ Sunil Kumar ${ }^{1}$ Sourya Acharya ${ }^{1}$ Anil K. Wanjari ${ }^{1}$ Shilpa Bawankule ${ }^{1, \odot}$ \\ Sachin Agrawal ${ }^{1}$ Ashlesha Shukla ${ }^{2}$
}

${ }^{1}$ Department of Medicine, Datta Meghe Institute of Medical Sciences, Jawahar Lal Nehru Medical College (deemed to be university), Wardha, Maharashtra, India

2Department of Medicine, Institute of Medical Sciences and SUM

Hospital (deemed to be university), Bhubaneswar, Odisha, India

\begin{abstract}
Address for correspondence Sunil Kumar, MD, PhD, Department of Medicine, Jawahar Lal Nehru Medical College, Datta Meghe Institute of Medical Sciences (deemed to be university), Wardha 442001, Maharashtra, India (e-mail: sunilkumarmed@gmail.com).
\end{abstract}

\begin{abstract}
Keywords

- red cell distribution width

- platelet distribution width

- mortality

- morbidity

- critically ill

Introduction The red blood cell distribution width (RDW) is a measurement of variations in the size of red blood cells. As the width increases, the rate of mortality also increases, although the reason for it is still not known. On the other hand, platelet distribution width (PDW) is also useful in predicting morbidity and mortality in sepsis and other critically ill patients. In our study, we planned to study the impact of both RDW and PDW and evaluate their prognostic importance with outcome in patients admitted in medicine intensive care unit (MICU).

Material and Method In these cross-sectional observational studies, 1,300 patients were included who were admitted in MICU. Critically ill patients were defined on the basis of qSOFA score greater than 2. PDW and RDW were obtained from Coulter report of complete blood count. Parameters included in Acute Physiology and Chronic Health Evaluation (APACHE) IV scores were taken and APACHE IV score was calculated. Correlation of RDW and PDW with outcomes such as length of ICU stay, use of mechanical ventilator, and discharge/death was done.

Result The mean RDW (\%) for the entire study population was $15.17 \pm 3.01$. The RDW (\%) was significantly on the higher side in patients who succumbed to the disease as compared with the patients who were discharged. The correlation between the length of ICU stay (days) and RDW (\%) was moderately positive and was significant (rho $=0.37, p \leq 0.001)$. The correlation between the length of ICU stay (days) and PDW (\%) was moderately positive and was significant ( $r$ ho $=0.5, p \leq 0.001$ ).

Conclusion RDW and PDW were found as significant indicators for period of stay in ICU, requirement for mechanical ventilation, and mortality rate in patients admitted to ICUs. As these are simple, easy to conduct, universally available tests, they can be regularly incorporated in patients admitted in ICUs.
\end{abstract}

published online June 27, 2021
DOI https://doi.org/

10.1055/s-0041-1730883 ISSN 0974-2727
C 2021. The Indian Association of Laboratory Physicians.

This is an open access article published by Thieme under the terms of the Creative Commons Attribution-NonDerivative-NonCommercial-License, permitting copying and reproduction so long as the original work is given appropriate credit. Contents may not be used for commercial purposes, or adapted, remixed, transformed or built upon. (https://creativecommons.org/licenses/by-nc-nd/4.0/).

Thieme Medical and Scientific Publishers Pvt. Ltd. A-12, 2nd Floor, Sector 2, Noida-201301 UP, India 


\section{Introduction}

The red blood cell distribution width (RDW) is a measurement of variations in the size of red blood cells. ${ }^{1}$ Width of platelet distribution (PDW) is an index of platelet which tells about variation in size of platelet. ${ }^{2}$ Normal range for PDW is 10 to $17 \% .{ }^{3}$ Erythrocytes have variation in size, which becomes tiny during aging. ${ }^{4}$ Recent studies had reported associations of RDW and PDW in patients with community-acquired pneumonia, cardiac failure, pulmonary hypertension, and myocardial infarction in the general population..$^{5-9}$ As RDW increases, the rate of mortality also increases and the reason for it is still not known. In few studies it was suggested that an increased RDW is due to inflammatory state. ${ }^{10}$

There is always a change in the morphology on activation of platelet in the process of inflammation. ${ }^{11,12} \mathrm{Erez}$ et al proposed that there was more activation of thrombin during certain critically ill conditions due to which there was morphological alteration in platelet, and they appeared larger as they became spherical in shape and has developed pseudopodia. ${ }^{13}$ As a result, platelets with greater number of large size pseudopodia will cause variation in PDW. Hypercoagulability is other possible mechanism for higher variation in platelet size. ${ }^{14} \mathrm{Ahmad}$ and Waheed showed in his study that newborn with sepsis of late onset had a massive rise in PDW. ${ }^{15}$ Although few templates have been assessed to study the mortality and morbidity in intensive care units (ICUs) regarding RDW and PDW, they have been studied separately. In our study we have tried to study the impact of both RDW and PDW combined and to evaluate its prognostic importance with hospital mortality in patients who are critically ill; to predict outcome in patients admitted in medical intensive care units (MICUs) in terms of length of ICU stay, need for ventilator, and mortality; to compare red cell distribution width and platelet distribution width with Acute Physiology and Chronic Health Evaluation (APACHE) IV score.

\section{Material and Methods}

This cross-sectional study was accomplished in the MICU under Medicine department from October 2018 to July 2020 at rural teaching hospital at central India after clearance from the Institutional Ethical Committee with approval letter numbered DMIMS (DU)/IEC/2018-19/7555. All the consecutive/sequential patients regardless of gender, ethnicity, or reason for hospitalization who were admitted under MICU with qSOFA score $\geq 2$ were taken as critically ill and were included in the study. PDW and RDW were obtained from complete blood count Coulter report; parameters needed for calculation of APACHE IV scores were taken and calculation of APACHE IV score was done using internet-based online module. Correlation of RDW and PDW with outcome such as the use of mechanical ventilator, length of ICU stays and discharge, and death was done. Patients were transferred from another (surgical) ICU. Patients readmitted to MICU during the same hospital stay were excluded from the study. Flowchart showing plan of study is shown in $\boldsymbol{- F i g}$. 1

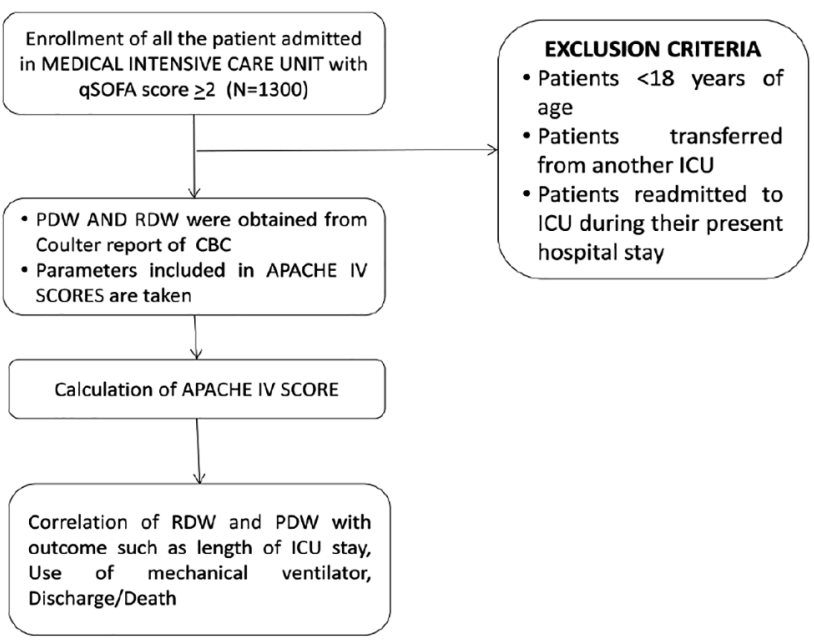

Fig. 1 Flow chart showing plan of study.

\section{Statistical Analysis}

Data were coded and recorded in MS Excel. Median/Means were used to elaborate the descriptive statistics and interquartile ranges/standard deviations (IQRs/SDs) for variables which were continuous and for variables which were categorical percentages/frequencies were used. Differences in the group for categorical data were compared with the help of chi-square test/Fisher's exact test. Statistical analyses were performed using IBM SPSS v23. Statistical significance was set at $p<0.05$.

\section{Result}

- Table 1 illustrates baseline characteristics of total 1,300 patients according to APACHE IV category. The mean age for the patient in the score group of 0 to 99 was $46.38 \pm 18.14$ while in 100 to 199 group was $50.87 \pm 16.59$ and in 200 to 286 group was $57.25 \pm 17.11$. In 0 to 99 group 230 patients were male and 141 patients were female while in 100 to 199 group 428 patients were male and 258 patients were female and in 200 to 286 group 167 patients were male and 76 were female. The mean RDW (\%) in 0 to 99 score group was 14.28 \pm 0.16 while in 100 to 99 score group it was $14.94 \pm 3.87$ and in 200 to 286 group it was $17.18 \pm 0.82$. The mean PDW (\%) in 0 to 99 score group was $9.29 \pm 0.23$ while in 100 to 99 score group it was $11.23 \pm 1.39$ and in 200 to 286 group it was $15.64 \pm 0.59$.

-Fig. 2 depicts the correlation between the length of ICU stay (days) and RDW (\%). Each point depicts an individual case. The trendline in blue color shows the general trend of correlation between both variables. The $95 \%$ confidence interval of the above trendline is shaded in gray color. The correlation between both the variables was explored with the help of nonparametric test. The length of ICU stay and RDW (\%), were moderately positively correlated and the correlation was statistically significant (rho $=0.37, p \leq 0.001$ ). For each unit increase in length of ICU stay (days), there was 0.09 units increase in RDW (\%). Contrarily, for increment 
Table 1 Baseline characteristics

\begin{tabular}{|c|c|c|c|c|}
\hline \multirow[t]{2}{*}{ Parameters } & \multicolumn{3}{|c|}{ APACHE IV score category } & \multirow[t]{2}{*}{$p$-Value } \\
\hline & $\begin{array}{l}0-99 \\
(n=371)\end{array}$ & $\begin{array}{l}100-199 \\
(n=686)\end{array}$ & $\begin{array}{l}200-286 \\
(n=243)\end{array}$ & \\
\hline Age (Years) ${ }^{* * *}$ & $46.38 \pm 18.14$ & $50.87 \pm 16.59$ & $\begin{array}{l}57.25 \pm \\
17.11\end{array}$ & $<0.0011$ \\
\hline \multicolumn{5}{|l|}{$\mathrm{Age}^{* * *}$} \\
\hline$<40 y$ & $146(39.4 \%)$ & $168(24.5 \%)$ & $40(16.5 \%)$ & \multirow[t]{3}{*}{$<0.0012$} \\
\hline $40-60 y$ & $124(33.4 \%)$ & $306(44.6 \%)$ & 95 (39.1\%) & \\
\hline$>60 y$ & $101(27.2 \%)$ & $212(30.9 \%)$ & $108(44.4 \%)$ & \\
\hline \multicolumn{5}{|l|}{ Gender } \\
\hline Male & $230(62.0 \%)$ & $428(62.4 \%)$ & $167(68.7 \%)$ & \multirow[t]{2}{*}{0.1662} \\
\hline Female & $141(38.0 \%)$ & $258(37.6 \%)$ & $76(31.3 \%)$ & \\
\hline \multicolumn{5}{|l|}{ Outcome ${ }^{* * *}$} \\
\hline Discharge & 368 (99.2\%) & $666(97.1 \%)$ & $11(4.5 \%)$ & \multirow[t]{2}{*}{$<0.0012$} \\
\hline Death & $3(0.8 \%)$ & $20(2.9 \%)$ & $232(95.5 \%)$ & \\
\hline APACHE IV score sc* $^{* *}$ & $76.16 \pm 8.47$ & $126.35 \pm 20.61$ & $\begin{array}{l}250.35 \pm \\
18.55\end{array}$ & $<0.0011$ \\
\hline $\operatorname{RDW}(\%)^{* * *}$ & $14.28 \pm 0.16$ & $14.94 \pm 3.87$ & $17.18 \pm 0.82$ & $<0.0011$ \\
\hline $\operatorname{PDW}(\%)^{* * *}$ & $9.29 \pm 0.23$ & $11.23 \pm 1.39$ & $15.64 \pm 0.59$ & $<0.0011$ \\
\hline Length of ICU stay (Days) ${ }^{* * *}$ & $2.27 \pm 0.83$ & $8.59 \pm 4.37$ & $5.72 \pm 6.13$ & $<0.0011$ \\
\hline Mechanical ventilator (Required) ${ }^{* * *}$ & $0(0.0 \%)$ & $77(11.2 \%)$ & $\begin{array}{l}243 \\
(100.0 \%)\end{array}$ & $<0.0012$ \\
\hline Number of co-morbidities $* * *$ & $3.26 \pm 1.65$ & $4.25 \pm 1.58$ & $6.51 \pm 1.73$ & $<0.0011$ \\
\hline Hypertension (Present) ${ }^{* * *}$ & 165 (44.5\%) & $400(58.3 \%)$ & $181(74.5 \%)$ & $<0.0012$ \\
\hline Diabetes (Present) & $25(6.7 \%)$ & $49(7.1 \%)$ & $22(9.1 \%)$ & 0.5292 \\
\hline Renal disease (Present) ${ }^{* * *}$ & $95(25.6 \%)$ & $254(37.0 \%)$ & $168(69.1 \%)$ & $<0.0012$ \\
\hline Neurological disease (Present) ${ }^{* * *}$ & $89(24.0 \%)$ & $157(22.9 \%)$ & $117(48.1 \%)$ & $<0.0012$ \\
\hline Cardiovascular disease (Present) ${ }^{* * *}$ & $229(61.7 \%)$ & $558(81.3 \%)$ & $240(98.8 \%)$ & $<0.0012$ \\
\hline Respiratory disease (Present) $* * *$ & $30(8.1 \%)$ & $121(17.6 \%)$ & $207(85.2 \%)$ & $<0.0012$ \\
\hline Liver disease (Present) ${ }^{* * *}$ & $65(17.5 \%)$ & $159(23.2 \%)$ & $103(42.4 \%)$ & $<0.0012$ \\
\hline $\begin{array}{l}\text { Immunocompromised state } \\
\text { (Present) }{ }^{* * *}\end{array}$ & $73(19.7 \%)$ & $255(37.2 \%)$ & $75(30.9 \%)$ & $<0.0012$ \\
\hline $\begin{array}{l}\text { Hematological abnormality } \\
\text { (Present) }{ }^{* * *}\end{array}$ & $167(45.0 \%)$ & $386(56.3 \%)$ & $185(76.1 \%)$ & $<0.0012$ \\
\hline Sepsis (Present) ${ }^{* * *}$ & $116(31.3 \%)$ & $304(44.3 \%)$ & $168(69.1 \%)$ & $<0.0012$ \\
\hline Dyselectrolytemia (Present) ${ }^{* * *}$ & $50(13.5 \%)$ & $151(22.0 \%)$ & 97 (39.9\%) & $<0.0012$ \\
\hline Other disorders (present) ${ }^{* * *}$ & 106 (28.7\%) & 108 (15.7\%) & $18(7.4 \%)$ & $<0.0012$ \\
\hline
\end{tabular}

Abbreviations: APACGE, Acute Physiology and Chronic Health Evaluation; ICU, intensive care unit; PDW, platelet distribution width; RDW, red blood cell distribution width.

*** denotes statistically significant.

in each unit of RDW (\%), the length of ICU stay (days) was increased by 0.25 units.

The area under the ROC curve (AUROC) for RDW (\%) predicting outcome: death versus outcome: discharge was 0.966 (95\% CI: 0.954-0.977), thus demonstrating excellent diagnostic performance. It was statistically significant $(p \leq 0.001)$ as evident in - Fig. 3. At a cutoff of RDW (\%) $\geq 15.9$, it predicts outcome: death and the sensitivity was $88 \%$, while specificity was $96 \%$. The odds ratio $(95 \% \mathrm{CI})$ for outcome: 1 when RDW (\%) is $\geq 15.9$ was 167.67 (103.5-271.61). The relative risk (95\% CI) for outcome: 1 when RDW (\%) is $\geq 15.9$ was 26 (18.67-36.32).

-Fig. 4 depicts the correlation between the length of ICU stay (days) and PDW (\%). Each point depicts an individual case. The trendline in blue color shows the general trend of correlation between both the variables. The 95\% confidence interval of the above trendline is shaded in gray color. The correlation in between both the variables was explored with the help of nonparametric test. The length of ICU stay and PDW (\%) were moderately positive correlated and the 


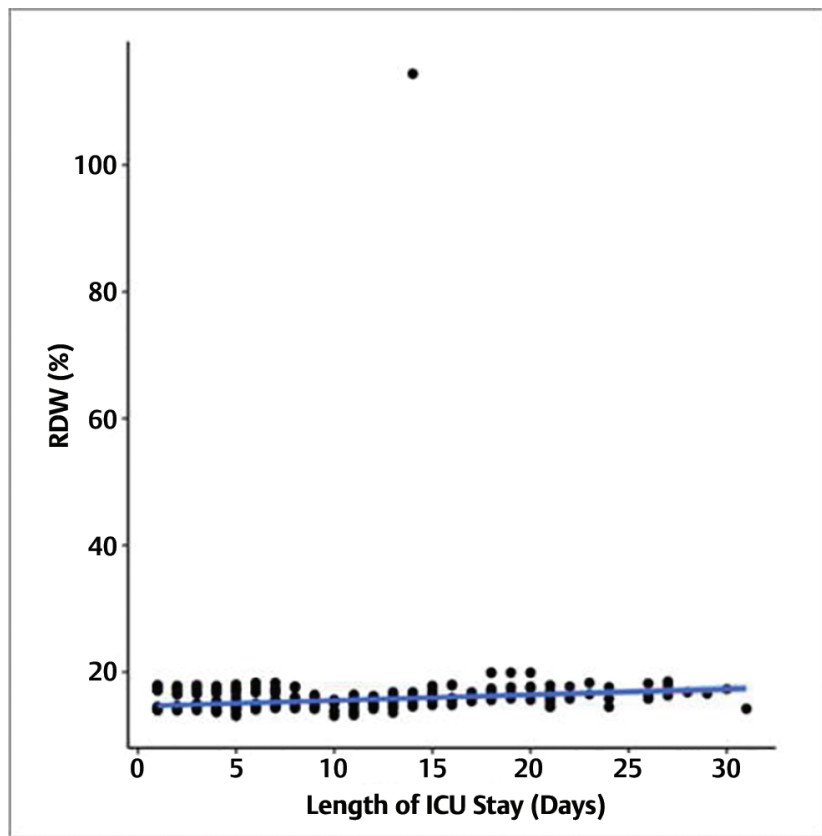

Fig. 2 Correlation between length of ICU stay (days) and RDW (\%) $(n=1,300)$.

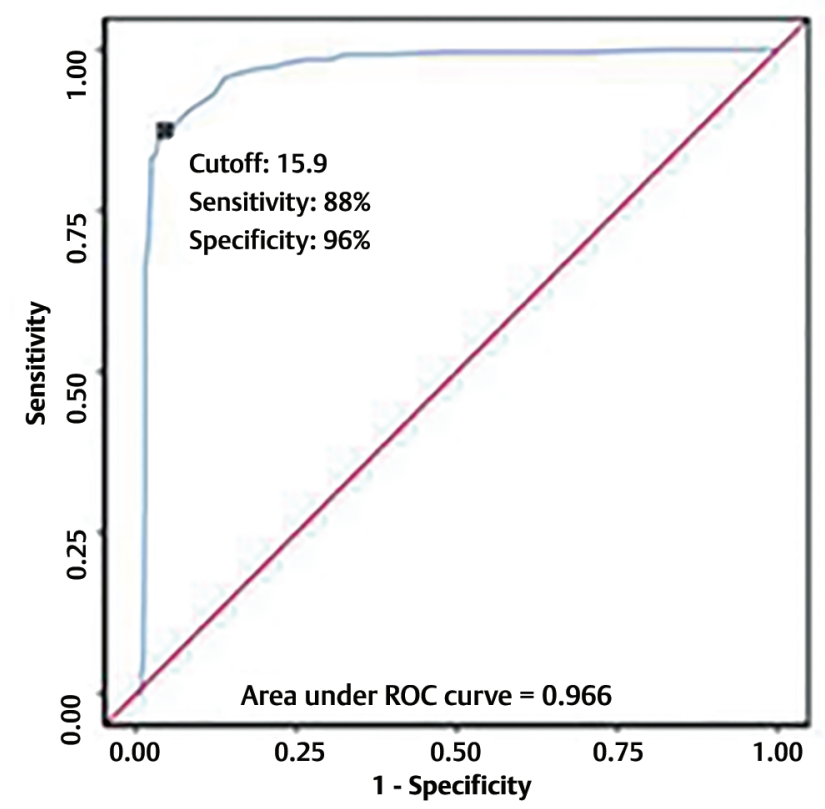

Fig. 3 ROC curve analysis showing diagnostic performance of RDW (\%) in predicting outcome: death vs outcome discharge $(n=1,300)$.

correlation was statistically significant (rho $=0.5, p \leq 0.001$ ) as evident in Fig. 4. For each unit increase in the length of ICU stay (days), there was 0.16 units increase in PDW (\%). Contrarily, for increment in each unit of PDW (\%), the length of ICU stay (days) increases by 0.71 units.

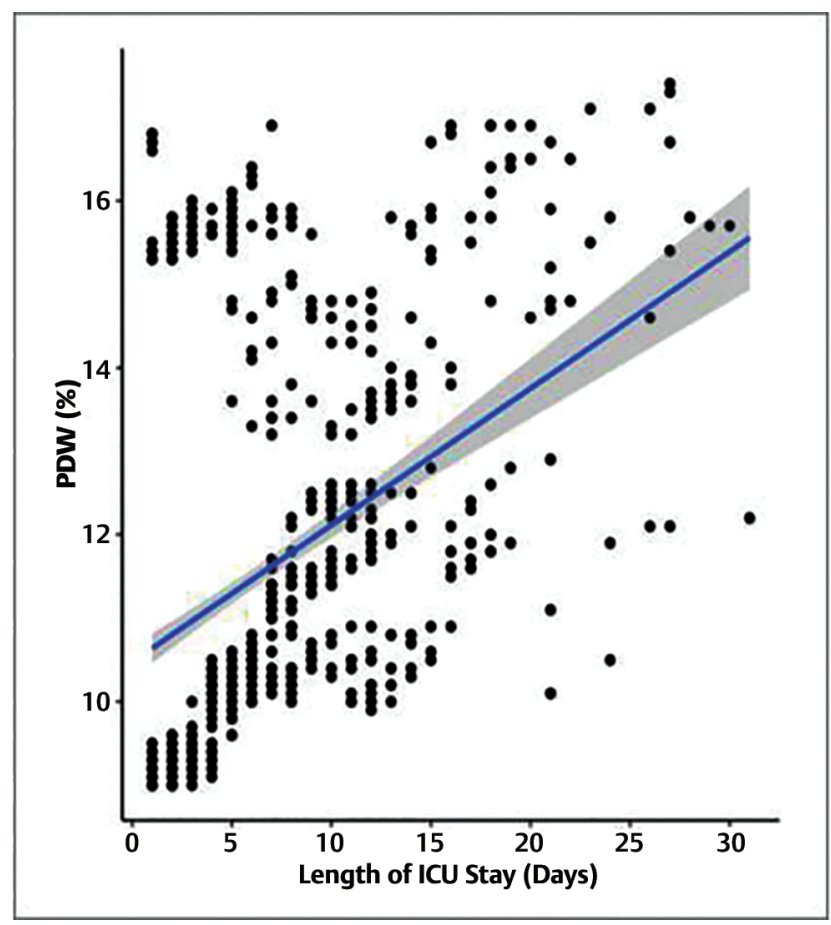

Fig. 4 Correlation between length of ICU stay (days) and PDW (\%) $(n=1,300)$.

The AUROC for PDW (\%) predicting outcome: death versus outcome: discharge was 0.973 (95\% CI: 0.961-0.985), thus demonstrating excellent diagnostic performance. It was statistically significant $(p \leq 0.001)$ as evident in - Fig. $\mathbf{5}$. At a cutoff of PDW $(\%) \geq 14.1$, it predicts outcome: death and sensitivity was $97 \%$, while the specificity was $97 \%$. The odds ratio $(95 \% \mathrm{CI})$ for outcome: 1 when $\mathrm{PDW}(\%)$ is $\leq 14.1$ was 1009.91 (458.53-2224.31). The relative risk ( $95 \% \mathrm{CI}$ ) for outcome: 1 when PDW (\%) is $\leq 14.1$ was 113.5 (57.74-223.97).

APACHE IV score, PDW (\%), and RDW (\%) significantly predicted outcome: death, as evident in $\boldsymbol{- F i g . ~} \mathbf{6}$

\section{Discussion}

The current study analyzed the impact of RDW and PDW in patients who were critically ill and admitted in MICU. The study predicted outcome in patients of MICUs with respect to the length of stay in ICU, the need for ventilator and death and compared RDW and PDW with APACHE IV score.

The mean age for the patients was $50.78 \pm 17.51$ years. $63.5 \%$ of the patients were males while $36.5 \%$ patients were females. In a study by Pal and Prashant ${ }^{16}$ from Northeast India, authors audited reasons for mortality in patients admitted to MICUs. They noted that high number of patients with mortality had sepsis at $26.3 \%$, stroke in $19.9 \%$ of the patients, and COPD in $13.9 \%$ of the patients. They noted that high number of deaths occurred in patients above 60 years. $10.5 \%$ of the patients had diabetes, $16.5 \%$ were hypertensive in this study. 


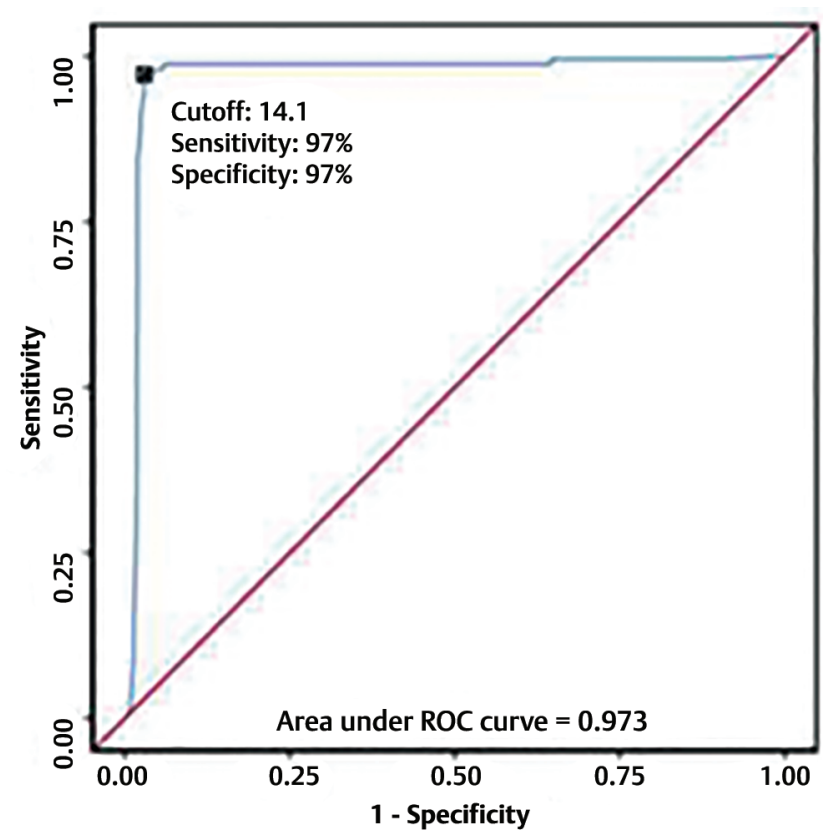

Fig. 5 ROC curve analysis showing diagnostic performance of PDW (\%) in predicting outcome: death vs outcome discharge $(n=1,300)$.

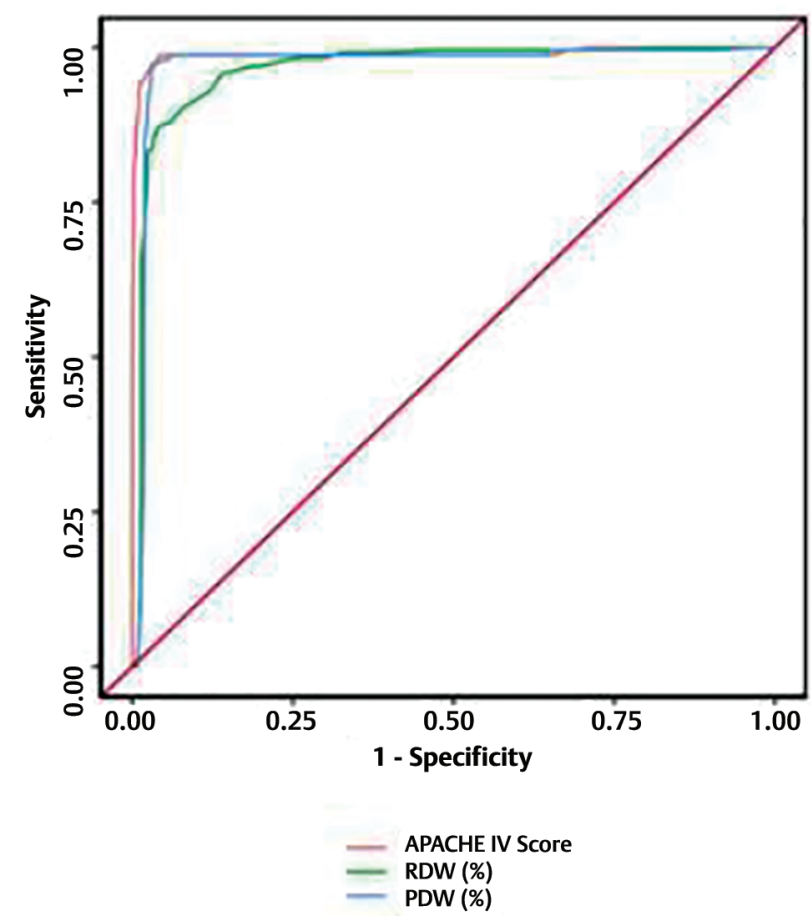

Fig. 6 Comparison of the diagnostic performance of various predictors in predicting outcome: death vs outcome discharge $(n=1,300)$.

In another study by Madani et al ${ }^{17}$ authors evaluated patterns of ICU admissions and mortality. Of 140 patients $63.6 \%$ had cardiovascular events and $26.4 \%$ had infections. The death rate was $10.7 \%$.
The patterns of ICU admission might differ in different geographical areas and it would also differ based on specialty services provided. There can be a rural and urban variation considering differences in risk factors and underlying medical conditions. It should be noted that presence of multiple co-morbidities is associated with increased risk of longer duration of hospitalization, increased ICU stay, and mortality rate. ${ }^{18}$

The mean RDW (\%) for the entire study population was $15.17 \pm 3.01$. The mean (SD) of RDW (\%) in the age group of $<40$ years was $14.81 \pm 1.11$, in age group of 40 to 60 years it was $15.27 \pm 4.49$, while in the age group $>60$ years it was $15.34 \pm 1.28$. The median (IQR) of RDW (\%) in patients with age group of $<40$ years was $14.4 \pm 0.9$, in 40 to 60 years age group it was $14.6 \pm 1.1$, and in the age group of $>60$ it was $14.9 \pm 1.9$. The RDW (\%) in patient with age group of $<40$ years ranged from 13.1 to 19.9 , while in 40 to 60 years ranged from 13.2 to 14.4 and in age group of $>60$ years ranged from 13.3 to 19.9. The difference in terms of RDW between the three age groups was significant $\left(X^{2}=43.725\right.$, $p \leq 0.001$ ). The difference in gender distribution in terms of RDW (\%) was not significant $(U=207431.000, p=0.077)$. In a study by Hoffmann et al, ${ }^{19}$ authors noted that there is an increase in RDW with increasing age, however, authors noted that this was not gender specific. This corresponds with our study.

The difference in both the groups (death vs. discharge) with regards to RDW (\%) was significant $(U=9178.500, p \leq$ 0.001 ), with the highest median RDW (\%) in the outcome: death group. The mean (SD) of RDW (\%) in those discharged was $14.72 \pm 3.18$ while those who died was $16.99 \pm 0.80$. The median (IQR) of RDW (\%) in the outcome: discharge group was $14.4 \pm 0.7$, while in the outcome: death group was $17.2 \pm 0.9$. The RDW (\%) in the outcome: discharge ranged from 13.1 to 14.4. while in the outcome: death it ranged from 14.2 to 18.3 . The RDW (\%) was remarkably higher in comparison with discharged patients. Various studies have noted that increase in RDW correlates with increase in mortality. Perlstein et $\mathrm{a}^{20}$ in a study noted that increased RDW is a predictor of increased mortality. Senol et $\mathrm{a}^{21}$ noted that the mortality risk in acute pancreatitis patient is increased with increased RDW. Ani and Ovbiagele ${ }^{22}$ noted that the mortality was increased in patients with stroke with increased RDW.

The correlation between the length of ICU stays (days) and RDW (\%) was moderately positive and was significant (rho = $0.37, p \leq 0.001$ ). For each unit increase in the length of ICU stay (days), there is increment in the RDW (\%) by 0.09 units. Contrarily, for increase in each unit of RDW (\%), the length of ICU stay (days) increases by 0.25 units. Farzanegan and $\mathrm{Zangi}^{23}$ noted that the increase in RDW is associated with longer duration of ICU stay. Tonietto et $\mathrm{al}^{24}$ noted that elevated RDW is associated with increased chances for re-admission to ICU. Fujita et $\mathrm{al}^{25}$ similarly noted a correlation between RDW and length of stay in ICU and hospitalization duration. 
The mean (SD) of RDW (\%) in the mechanical ventilator: required group was $17.07 \pm 5.58$ while in the mechanical ventilator: not required group was $14.55 \pm 0.55$. The median (IQR) of RDW (\%) in the mechanical ventilator: required group was $17.15 \pm 1.35$ while in the mechanical ventilator: not required group was $14.4 \pm 0.6$. The RDW (\%) in the mechanical ventilator: required group ranged from 13.8 to 14.4 while in the mechanical ventilator: not required group ranged from 13.1 to 16.8 . The difference between both the groups with respect to RDW (\%) was significant $(U=294104.500, p \leq 0.001)$, with mechanical ventilator: required group having the highest median RDW (\%). Otero et $\mathrm{al}^{26}$ noted that increased RDW is associated with decreased ventilator free time in critically ill patients. Meynaar et $\mathrm{al}^{27}$ similarly observed that increased RDW correlates with increased chances for intubation in patients who were critically ill.

The AUROC for RDW (\%) predicting outcome: death versus outcome: discharge was 0.966 (95\% CI: 0.954-0.977), thus demonstrating excellent diagnostic performance. It was statistically significant $(p \leq 0.001)$ as observed by various studies. $\mathrm{RDW}^{20-22}$ is a promising prognostic factor in predicting death in patients requiring ICU support which correlated with our study.

The mean (SD) of PDW (\%) in the age group of $<40$ years was $10.93 \pm 2.24$ while in the 40 to 60 years age group it was $11.51 \pm 2.31$, and in the age group of $>60$ years group it was $11.97 \pm 2.53$. The median (IQR) of PDW (\%) in the age group of $<40$ years was $10.2 \pm 2.1$, while in 40 to 60 years age group it was $10.5 \pm 2.4$. In $>60$ years age group it was 10.9 \pm 4.8 . The PDW (\%) in the age group $<40$ years ranged from 9 to 17.1 , while in the age group 40 to 60 years it ranged from 9 to 17.3, and in the age group of $>60$ years it ranged from 9 to 17.4. The difference in terms of PDW (\%) between the three age groups was significant $\left(X^{2}=49.206, p \leq 0.001\right)$, with the highest median PDW (\%) in the age group $>60$ years. The difference in gender distribution in terms of PDW (\%) was not significant $(U=206445.000, p=0.107)$. Use of PDW has been utilized in various workers in assessing prognosis in various diseases such as gastric cancer, appendicitis, thyroid disorders, etc. ${ }^{28,29}$ Hoffmann and van den Broek ${ }^{30}$ did not note any significant correlation between gender and platelet indices but however, noted age of the patient might have some association.

The mean (SD) of PDW (\%) in the outcome: discharge group was $10.53 \pm 1.48$ while in the outcome: death group was $15.47 \pm 0.87$. The median (IQR) of PDW (\%) in the outcome: discharge group was $10.2 \pm 1.8$ while in the outcome: death group was $15.6 \pm 0.4$. The PDW (\%) in the outcome: discharge ranged from 9 to 17.4, while in the outcome: death ranged from 9.1 to 17.1. The difference between both the groups with respect to PDW (\%) was significant $(U=7162.500, p \leq 0.001)$, and the outcome: death group had the highest median PDW (\%). Zhan et $\mathrm{a}^{31}$ noted in a study that increase in PDW was noted in fatal cases when compared with the survivors. Simani et a ${ }^{32}$ observed higher PDW values in patients who had a fatal course when suffering from post-neurosurgical meningitis when compared with the survivors. Gao et $\mathrm{al}^{33}$ in a study on patients with septic shock noted higher chances of death in patients with increased PDW.

The correlation between length of ICU stay (days) and PDW (\%) was moderately positive and was significant (rho $=0.5, p \leq 0.001)$. For each unit increase in length of ICU stay (days), there was increment in PDW (\%) by 0.16 units. Contrarily, for each unit increase in PDW (\%), the length of ICU stay (days) increases by 0.71 units. Sezgi et a ${ }^{34}$ observed in patients admitted to respiratory ICU that patients with higher value of PDW had longer duration of stay in ICU and higher mortality. Zhang et $\mathrm{al}^{3}$ noted higher mean duration of ICU stay in critically ill Chinese patients when correlated with increased PDW.

The mean (SD) of PDW (\%) in the mechanical ventilator: required group was $15.30 \pm 1.03$ while of mechanical ventilator: not required group was $10.26 \pm 1.01$. The median (IQR) of PDW (\%) in the mechanical ventilator: required group was $15.5 \pm 1$. while in the mechanical ventilator: not required group was $10.2 \pm 1.5$. The PDW (\%) in the mechanical ventilator: required group ranged from 10.4 to 17.4. The PDW (\%) in the mechanical ventilator: not required group ranged from 9 to 13.7. The difference in between both the groups with respect to PDW (\%) was significant $(U=312187.000, p$ $\leq 0.001$ ), and the mechanical ventilator: required group had the highest median PDW (\%). Tzur et al ${ }^{35}$ noted increased chances of mechanical ventilation in patients with a higher mean PDW at the time of admission. Dundar et $\mathrm{al}^{36}$ observed increased need for mechanical ventilation in patients with organophosphorus poisoning having elevated PDW.

The AUROC for PDW (\%) in predicting outcome: death versus outcome: discharge was 0.973 (95\% CI: 0.961-0.985), thus demonstrating excellent diagnostic performance. It was statistically significant $(p \leq 0.001)$. At a cut off of PDW [\%] $>14.1$, it predicts outcome: death with sensitivity $97 \%$ and specificity $97 \%$. PDW, as observed from our study, can be an important prognostic marker in patients who are admitted in ICUs.

In APACHE IV, the diagnosis on admission to the ICU, days of stay in the hospital before ICU care, thrombolytic therapy, and mechanical ventilation are added and this is uncommonly used. Higher scores of APACHE IV are associated with more critical illness with increased chances of ventilation, increased ICU stay, increased hospitalization, and mortality. ${ }^{37}$ Considering higher scores of APACHE IV with increased levels of PDW, the scoring system corresponds with our findings related to RDW and PDW being markers for increased ICU stay, increased need for mechanical ventilation, and increased mortality.

\section{Limitations}

The study population was nonhomogeneous. As such confounding effect of underlying medical conditions such as causes of sepsis like chronic kidney disease, liver disease, 
ARDS on mortality was not studied and cannot be totally excluded. The study did not evaluate other platelet and red cells indices. Serial, multiple PDW and RDW estimations and its effect on the clinical outcomes were not done.

\section{Conclusion}

RDW and PDW were found as significant indicators for period of stay in ICU, requirement for mechanical ventilation, and mortality rate in patients admitted to ICUs. The indices also correlated with APACHE IV scoring system, with higher RDW and PDW values in patients leading to a higher APACHE IV score, which in turn correlated with the period of stay in ICU, requirement for mechanical ventilation, and mortality rate. As these are simple, easy to conduct, and universally available tests, they can be regularly incorporated in patients admitted to ICUs. Adequate interventions can also be planned based on these parameters for better patient outcomes.

\section{Conflict of Interest}

None declared.

\section{References}

1 Lippi G, Plebani M. Red blood cell distribution width (RDW) and human pathology. One size fits all. Clin Chem Lab Med 2014;52(9):1247-1249

2 Kaito K, Otsubo H, Usui N, et al. Platelet size deviation width, platelet large cell ratio, and mean platelet volume have sufficient sensitivity and specificity in the diagnosis of immune thrombocytopenia. Br J Haematol 2005;128(5):698-702

3 Zhang S, Cui Y-L, Diao M-Y, Chen D-C, Lin Z-F. Use of platelet indices for determining illness severity and predicting prognosis in critically ill patients. Chin Med J (Engl) 2015;128(15):2012-2018

4 Montagnana M, Cervellin G, Meschi T, Lippi G. The role of red blood cell distribution width in cardiovascular and thrombotic disorders. Clin Chem Lab Med 2011;50(4):635-641

5 Dabbah S, Hammerman H, Markiewicz W, Aronson D. Relation between red cell distribution width and clinical outcomes after acute myocardial infarction. Am J Cardiol 2010;105(3):312-317

6 Pascual-Figal DA, Bonaque JC, Redondo B, et al. Red blood cell distribution width predicts long-term outcome regardless of anaemia status in acute heart failure patients. Eur J Heart Fail 2009;11(9):840-846

7 Braun E, Domany E, Kenig Y, Mazor Y, Makhoul BF, Azzam ZS. Elevated red cell distribution width predicts poor outcome in young patients with community acquired pneumonia. Crit Care 2011;15(4):R194

8 Hampole CV, Mehrotra AK, Thenappan T, Gomberg-Maitland M, Shah SJ. Usefulness of red cell distribution width as a prognostic marker in pulmonary hypertension. Am J Cardiol 2009;104(6):868-872

9 Patel KV, Ferrucci L, Ershler WB, Longo DL, Guralnik JM. Red blood cell distribution width and the risk of death in middle-aged and older adults. Arch Intern Med 2009;169(5):515-523

10 Bazick HS, Chang D, Mahadevappa K, Gibbons FK, Christopher KB. Red cell distribution width and all-cause mortality in critically ill patients. Crit Care Med 2011;39(8):1913-1921

11 Babu E, Basu D. Platelet large cell ratio in the differential diagnosis of abnormal platelet counts. Indian J Pathol Microbiol 2004;47(2):202-205

12 Artunc Ulkumen B, Pala HG, Calik E, Oruc Koltan S. Platelet distribution width (PDW): a putative marker for threatened preterm labour. Pak J Med Sci 2014;30(4):745-748

13 Erez O, Romero R, Hoppensteadt D, et al. Premature labor: a state of platelet activation? J Perinat Med 2008;36(5):377-387

14 Ulucan Ş, Keser A, Kaya Z, et al. Association between PDW and long term major adverse cardiac events in patients with acute coronary syndrome. Heart Lung Circ 2016;25(1):29-34

15 Ahmad MS, Waheed A. Platelet counts, MPV and PDW in culture proven and probable neonatal sepsis and association of platelet counts with mortality rate. J Coll Physicians Surg Pak 2014;24(5):340-344

16 Pal A, Prashant K. An audit on pattern of mortality in a medicine ICU at tertiary care hospital of North-East India. Int J Med Biomed Stud 2020;4(2):199-201

17 Madani TA, Ghabrah TM, Albarrak AM, et al. Causes of admission to intensive care units in the Hajj period of the Islamic year 1424 (2004) Ann Saudi Med 2007;27(2):101-105

18 McManus DD, Nguyen HL, Saczynski JS, Tisminetzky M, Bourell P, Goldberg RJ. Multiple cardiovascular comorbidities and acute myocardial infarction: temporal trends (1990-2007) and impact on death rates at 30 days and 1 year. Clin Epidemiol 2012;4:115-123

19 Hoffmann JJ, Nabbe KCAM, van den Broek NMA. Effect of age and gender on reference intervals of red blood cell distribution width (RDW) and mean red cell volume (MCV) Clin Chem Lab Med 2015;53(12):2015-2019

20 Perlstein TS, Weuve J, Pfeffer MA, Beckman JA. Red blood cell distribution width and mortality risk in a community-based prospective cohort. Arch Intern Med 2009;169(6):588-594

21 Şenol K, Saylam B, Kocaay F, Tez M. Red cell distribution width as a predictor of mortality in acute pancreatitis. Am J Emerg Med 2013;31(4):687-689

22 Ani C, Ovbiagele B. Elevated red blood cell distribution width predicts mortality in persons with known stroke. J Neurol Sci 2009;277(1-2):103-108

23 Farzanegan B, Zangi M. Predictor factors for sepsis diagnosis, length of ICU stay and mortality in ICU. J Cell Mol Anesth 2017;2(2):55-62

24 Tonietto TA, Boniatti MM, Lisboa TC, et al. Elevated red blood cell distribution width at ICU discharge is associated with readmission to the intensive care unit. Clin Biochem 2018;55:15-20

25 Fujita B, Strodthoff D, Fritzenwanger M, et al. Altered red blood cell distribution width in overweight adolescents and its association with markers of inflammation. Pediatr Obes 2013;8(5):385-391

26 Otero TM, Canales C, Yeh DD, Hou PC, Belcher DM, Quraishi SA. Elevated red cell distribution width at initiation of critical care is associated with mortality in surgical intensive care unit patients. J Crit Care 2016;34:7-11

27 Meynaar IA, Knook AHM, Coolen S, et al. Red cell distribution width as predictor for mortality in critically ill patients. Neth J Med 2013;71(9):488-493

28 Aydogan A, Akkucuk S, Arica S, et al. The analysis of mean platelet volume and platelet distribution width levels in appendicitis. Indian J Surg 2015;77(suppl 2) :495-500

29 Ren X, Meng Z, Liu M, et al. No associations exist between mean platelet volume or platelet distribution width and thyroid function in Chinese. Medicine (Baltimore) 2016;95(40):e4573 
30 Hoffmann JJ, van den Broek NMA, Curvers J. Reference intervals of reticulated platelets and other platelet parameters and their associations. Arch Pathol Lab Med 2013;137(11):1635-1640

31 Zhang Z, Xu X, Ni H, Deng H. Platelet indices are novel predictors of hospital mortality in intensive care unit patients. J Crit Care 2014;29(5):885.e1-885.e6

32 Simani L, Oroei M, Sadeghi H, et al. Platelet indices for predicting patient outcomes in post-neurosurgical meningitis. Arch Neurosci 2019;6(2):e82911

33 Gao Y, Li Y, Yu X, et al. The impact of various platelet indices as prognostic markers of septic shock. PLoS ONE 2014;9(8):e103761

34 Sezgi C, Taylan M, Kaya H, et al. Alterations in platelet count and mean platelet volume as predictors of patient outcome in the respiratory intensive care unit. Clin Respir J 2015;9(4):403-408
35 Tzur I, Barchel D, Izhakian S, et al. Platelet distribution width: a novel prognostic marker in an internal medicine ward. J Community Hosp Intern Med Perspect 2019;9(6):464-470

36 Dundar ZD, Koylu R, Ergin M, Gunaydin YK, Ozer R, Cander B. Prognostic value of red cell distribution width in patients with organophosphate poisoning. J Acad Emerg Med 2015;14(2):65-69

37 Zimmerman JE, Kramer AA, McNair DS, Malila FM. Acute Physiology and Chronic Health Evaluation (APACHE) IV: hospital mortality assessment for today's critically ill patients. Crit Care Med 2006;34(5):1297-1310 